\title{
Yenidoğan Yoğun Bakım Ünitesinde Takip Edilen Preterm Yenidoğanların Retrospektif Analizi
}

\section{Retrospective Analysis of Preterm Neonates Admitted To Neonatal Intensive Care Unit}

\author{
Osman Özvarol ${ }^{1}$, Sevil Bilir Göksügür ${ }^{1}$, Mervan Bekdaş ${ }^{1}$, Nuriye Tarakçı ${ }^{2}$, Hüseyin Altunhan ${ }^{2}$
}

${ }^{1}$ Abant İzzet Baysal

Üniversitesi Tıp Fakültesi,

Çocuk Sağlığı ve Hastalıkları, Bolu, Türkiye.

${ }^{2}$ Necmettin Ernbakan Üniversitesi Tip Fakültesi, Çocuk Sağlığı ve Hastalıkları, Neonataoloji BD, Konya, Türkiye.

\section{Corresponding Author:}

Dr . Sevil Bilir Göksügür

Address : Abant İzzet

Baysal Üniversitesi Tip

Fakültesi, Çocuk Sağlığı ve

Hastalıkları, Bolu, Türkiye

E-mail:

sevilbilir@yahoo.com

\section{Başvuru Tarihi/Received :}

01-10-2014

\section{Kabul Tarihi/Accepted:}

20-10-2014

\section{ÖZET}

Amaç: Bu çalışmanın amacı, yoğun bakım ünitesine alınan preterm olguları retrospektif olarak değerlendirmek, perinatal problemlerini ve klinik sonuçları etkileyen faktörleri belirlemektir.

Gereç ve Yöntem: Abant İzzet Baysal Üniversitesi Tıp Fakültesi Yenidoğan Yoğun Bakım Ünitesinde 2012-2013 yılları arasında yatarak tedavi görmüş preterm bebeklerin ve annelerinin demografik özellikleri ve tıbbi kayıtları geriye dönük olarak incelenmiştir.

Bulgular: Çalışmada 146 preterm bebek incelendi. \%55,5'i $(n=81)$ sınırda prematüre, $\% 25,3$ 'ü $(n=37)$ orta derecede prematüre, $\% 15,1$ ' $i(n=22)$ ileri derecede prematüre ve $\% 4,1$ ' $i(n=6)$ immatür idi. Altı tanesi exitus olmuştu. Yaşayan en küçük bebek 700 gram olarak 30. gebelik haftasında doğmuştu. Mortaliteyi etkileyen faktörler olarak; doğum ağırlı̆̆ı, gebelik haftası ve Apgar skorlarının düşüklügü, normal vajinal yolla doğum ve ikiz eşi olmak bulunmuştur.

Sonuç: Preterm doğum yaygın olmakla birlikte intrauterin ortamda fetus ve anneden kaynaklanan çok sayıda faktörün kompleks ilişkisine dayanır. Preterm doğumlarda mortalite ve morbiditenin major belirleyicisi maturite derecesidir. Preterm bebekler term bebeklere göre organ hasarına, nörolojik gelişme geriliğine, kronik hastalıklara ve ölüme daha yatkındırlar. Preterm doğumların tamamen engellenmesi ulaşılabilir bir hedef olmasa da, hamile kadınların düzenli tıbbi takipleri ve yenidoğanların uygun tedavi ve takipleri morbidite ve mortaliteyi azaltacaktır.

\section{Anahtar kelimeler: Düşük doğum ağırlığı, mortalite, prematurite, preterm, yenidoğan}

\section{ABSTRACT}

Aim: The aim of this study is to evaluate the preterm cases that referred to neonatal intensive care unit retrospectively, and define the perinatal problems and factors associated with clinic outcomes of the patients.

Material and Method: Demographic data and medical records of preterm babies and their mothers, whose referred to Neonatal Intensive Care Unit of Abant Izzet Baysal University Medical Faculty between 2012 and 2013 were included and retrospectively evaluated.

Results: One hundred forty six preterm babies were revealed in the study. According to gestational age, there were $81(\% 55.5)$ late preterm, 37 (\%25.3) moderate preterm, $22(\% 15.1)$ extremely preterm, $6 \%$ (4.1) immature babies. Six of them had been exitus. Most premature baby who survived was born at 30 weeks with a birth weight of 700 grams. Risk factors of preterm mortality were found as lower gestational age, lower birth weight, lower Apgar scores, born by vaginal delivery and being a twin.

Conclusion: Preterm birth is therefore a common, complex condition that results from multiple interactions between the maternal and the fetal conditions in the intrauterine environment. Degree of maturity, therefore, is the major determinant of mortality and morbidity of preterm birth. Preterm infants are more vulnerable to organ injury, neurodevelopmental disability, chronic illness, and death than full term newborns. Although total prevention of preterm delivery is not achievable target; regular medical follow-up of pregnant women, appropriate treatment and follow-up of newborn will reduce the morbidity and mortality.

Key Words: Low birth weight, mortality, newborn, prematurity, preterm, 


\section{GíRiș}

Preterm doğum gelişmiş ülkeler de dâhil olmak üzere tüm dünyada neonatal mortalite ve morbidite nedenlerinin başında gelmektedir. Dünya genelinde sıklığının tüm yaşayan canlı doğumlar içinde \%11 olduğu tahmin edilmektedir (1). Son y1llarda neonataloji ile ilgili bilimsel ve teknolojik gelişmeler sayesinde ve yenidoğan yoğun bakım ünitelerinde bakım kalitesinin artmasıyla prematüre bebeklerin yaşam oranı belirgin artış göstermiştir. Ancak neonatal ve perinatal bakımdaki tüm gelişmelere karşın preterm doğum halen önemli ve önlenememiş bir sorun olarak kalmaya devam etmektedir. $\mathrm{Bu}$ bebeklerin bir kısmı doğumda veya doğum sonrası kaybedilirken, yaşayanlarda prematürite nedeniyle önemli sorunlar gelişebilmektedir.

Prematürite multifaktöriyel bir problemdir. Preterm doğumların yaklaşık \%75'i preterm travay ve preterm membran rüptürü sonras1 spontan olarak ortaya çıarken; geri kalan \% 25'i maternal hipertansiyon, diabet, plasenta previa, intrauterin gelişim geriliği gibi fetusu risk altında birakan medikal veya obstetrik problemler sonucunda oluşur. Endikasyonlu preterm doğumların önlenmesi altta yatan hastalığın önlenmesi ve tedavisine dayanır. Spontanpreterm doğumların yarıdan fazlası herhangi bir risk faktörü olmayan kadınlarda meydana gelir $(2,3)$.

Yenidoğan yoğun bakım ünitelerindeki (YYBÜ) bebeklerin çoğu prematüre yenidoğanlardır. Beş yaş altı çocuk ölümlerinin \% 38'i neonatal dönemdedir ve prematüre doğum \%28'lik bir oranla en önemli neonatal ölüm nedenidir. Bununla birlikte prematüre doğum sıklığı giderek artmaktadır. Afrika'dan sonra en yüksek prematüre doğum oranı Kuzey Amerika'dadır. Tek başına Amerika Birleşik Devletlerinde (ABD) \%12,7'dir. Son 25 yılda ABD'deki prematüre doğum sıklığ $1 \% 36$ oranında artmıştır (4). Türk Neonatoloji Derneği'nin 1999 yılında yapmış olduğu araştırmada ülkemizde perinatal ölüm hızı $\% 0.39$ bulunmuş ve bunun nedenleri arasında 2. siklıkta (\%26) prematürite yer almıştır (5).

Mevcut risklere rağmen preterm doğumların tümüyle önlenmesi mümkün olmasa da, daha iyi beslenme, sik doğumların önlenmesi, anne sağlığının düzeltilmesi, sosyoekonomik ve sosyokültürel yapının iyileştirilmesi, gebelik süresince yakın izlem ile preterm doğumların oranı azaltılabilir (6).

Prematüre bebeklerin fizyolojik ihtiyaçlarının belirlenebilmesi, ortaya çıkabilecek sorunların erken fark edilmesi ve erken tedavisi açısından prematüritenin sorunları konusunda deneyimli kişilerce izlenmeleri gerekmektedir. $\mathrm{Bu}$ bebeklerde mortalite ve morbiditeye neden olan sorunlar ne kadar iyi bilinirse bu problemlerle o kadar iyi baş edilebilir.

Bu çalışmada, AİBÜ Tıp Fakültesi Hastanesi, Çocuk Sağlığı ve Hastalıkları, Yenidoğan Yoğun Bakım Ünitesi'nde Ocak 2012 ve Temmuz 2013 tarihleri arasında prematürite tanıs1 ile yatırılıp takip ve tedavisi yapılan bebeklerin prenatal, natal ve postnatal sorunları ve demografik özellikler geriye dönük olarak değerlendirilerek prematür doğumların azaltılması ve preterm bebeklerin sekelsiz iyileşmesini sağlamak amaçlanmıştır.

\section{GEREÇ VE YÖNTEMLER}

Bu çalışma, AİBÜ Tıp Fakültesi Hastanesi, Çocuk Sağlığı ve Hastalıkları, Yenidoğan Yoğun Bakım Ünitesi'ne Ocak 2012 ve Temmuz 2013 tarihleri arasında yatırılarak izlenen 22-37 gebelik haftas1 arasında olan ( $>22$ gebelik haftas1, <37 gebelik haftas1) prematüre bebeklerin sorunları ve demografik özelliklerinin geriye dönük olarak incelendiği bir çalışmadır.

Çalışmaya dâhil edilen 146 prematüre bebeğin; cinsiyeti, gebelik yaşı, doğum ağırlığı, Apgar skoru, doğum şekli, doğum travması, annenin gebelik öyküsü (antenatal takip, erken membran rüptürü, annede hipertansiyon/diyabet 
varlığı, annede genitoüriner enfeksiyon varlığ1, antenatal steroid/tetanoz aşısı uygulamaları, annenin sigara/alkol kullanım öyküsü), prematüre bebeğin klinik durumu, uygulanan tedaviler ve vakanın nasıl sonuçlandığı hasta dosyalarından alınarak önceden hazırlanan formlara girildi.

Çalışmaya alınan vakalar, gebelik yaşlarına göre; sinırda prematüre (34 hafta ile 36 hafta 6 gün aras1), orta derecede prematüre (32 hafta ile 33 hafta 6 gün aras1), ileri derecede prematüre (28 hafta ile 31 hafta 6 gün arası) ve immatür (28 haftadan küçük) olarak gruplandırıldı. Doğum ağırlıklarına göre ise; çok çok düşük doğum ağırlığı (<1000 gr), çok düşük doğum ağırlığ1 (1000-1499 gr), düşük doğum ağırlığı (1500-2499 gr) ve normal doğum ağırlığı ( $\geq 2500$ gr) olarak gruplandırıldı.

Veri toplama formu aracılığıyla toplanan veriler Statistical Package for the Social Sciences ver. 15.0 (SPSS 15,0) programina girildi ve istatistiksel değerlendirmeleri yapıldı. Tanımlayıcı istatistikler sayı ve yüzde ile ifade edildi. Kategorik yapıdaki değişkenler arasındaki ilişkiler Ki-Kare ve Fischer'in kesin Ki-Kare testiyle incelendi. Sonuçlar \%95 güven aralığında değerlendirildi ve $\mathrm{p}<0.05$ değeri anlamlı kabul edildi.

\section{BULGULAR}

Çalışmamızda146 vaka incelendi. Bu vakaların \%53,4'ü $(n=78)$ erkek, \%46,6's1 (n=68) kız cinsiyetteydi. Vakaların gebelik yaşına göre gruplarına bakıldığında, \%55,5'i (n=81) sınırda prematüre, $\% 25,3^{\prime} \ddot{\mathrm{u}} \quad(\mathrm{n}=37)$ orta derecede prematüre, \%15,1'i $(\mathrm{n}=22)$ ileri derecede prematüreve \%4,1'i $(\mathrm{n}=6)$ immatürolarak saptand1.

Doğum ağırlığına göre değerlendirmede vakaların \%23,3'ü $\quad(n=34)$ normal doğum ağırlığında, \%52,1'i $\quad(n=76)$ düşük doğum ağırlığında, \%20,5'i (n=30) çok düşük doğum ağırlığında, \%4,1'i (n=6) çok çok düşük doğum ağırlığında bulundu. Yenidoğan yoğun bakım ünitemizde takibi yapılan ve şifa ile tabucu edilen doğum ağırlığı en düşük olan prematür bebek30 gebelik haftasinda sezeryan ile 700 gram doğmuştu. Çalışmaya alınan vakaların \%14,4'ü $(n=21)$ ikiz eşiydi. Vakaların \%72,6'sının $(n=106)$ doğumu hastanemizde gerçekleşmiş iken, $\% 27,4$ 'ü $(n=40)$ dış merkezden nakil yoluyla gelmişti. Doğum çeşidi; \%80,8'inin ( $\mathrm{n}=118)$ sezeryanla, $\% 19,2$ 'sinin $(\mathrm{n}=28)$ doğumu doğal yollardan gerçekleşmişti.

Vakaların genel karakteristikleri Tablo 1'de verilmiştir.

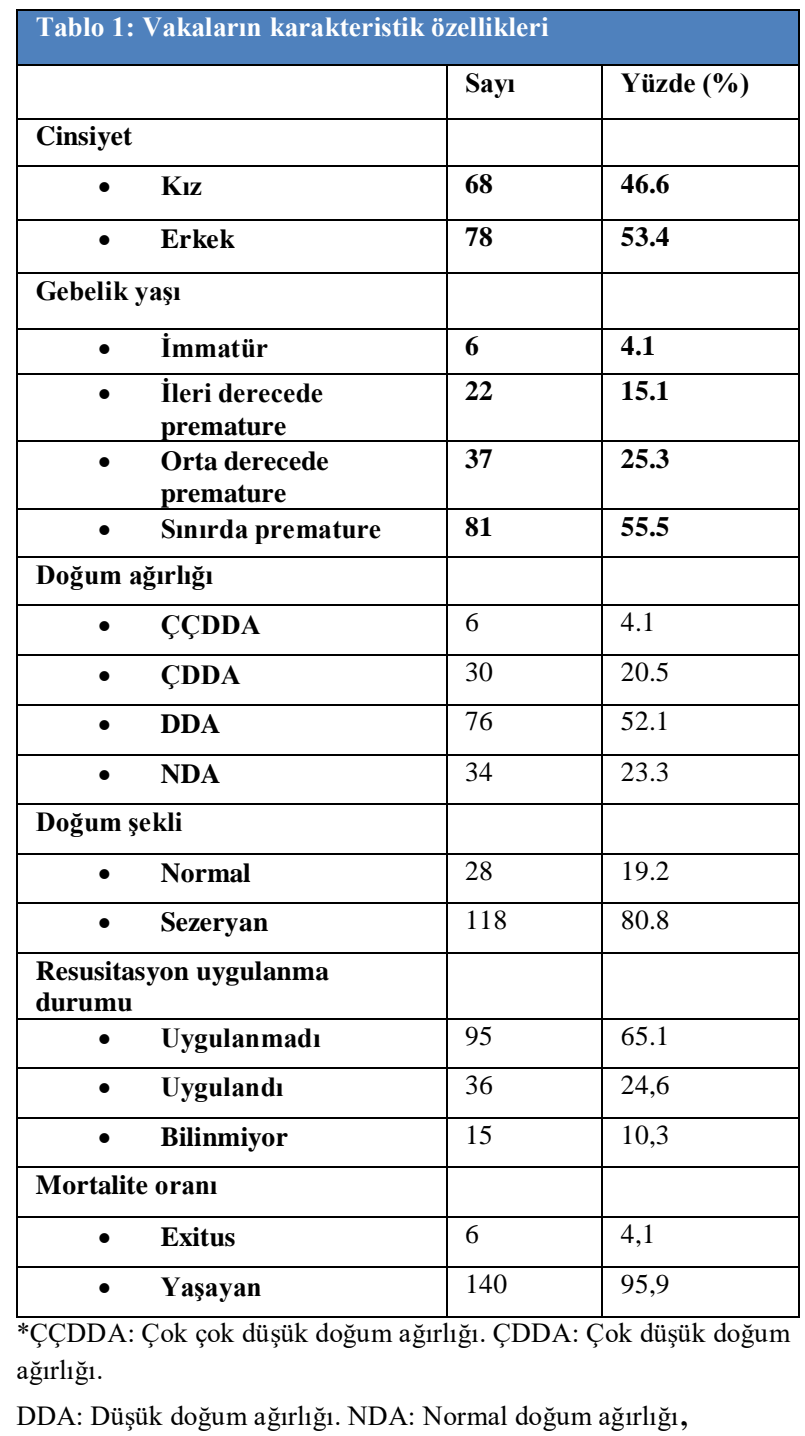


Vakaların annelerinin gebelikle ilgili komplikasyonları ve bebeklerin postnatal tespit edilmiş patolojileri sırasıyla Tablo 2'de ve Tablo 3'de verilmiştir.

\begin{tabular}{|l|c|c|}
\hline \multicolumn{2}{|c|}{ Tablo 2: Maternal takip ve komplikasyonlara ait özellikler } \\
\hline & Sayı & Yüzde (\%) \\
\hline Antenatal takip yapılmış olanlar & 140 & 95.9 \\
\hline Tetanoz aşısı yapılmış olanlar & 135 & 92,5 \\
\hline Antenatal steroit yapılmış olanlar & 63 & 43,1 \\
\hline Annede gebelikte alkol öyküsü & 0 & 0.0 \\
\hline Erken membran rüptürü & 26 & 17.8 \\
\hline Annede hipertansiyon & 51 & 34.9 \\
\hline Annede diyabetes mellitus & 16 & 11.0 \\
\hline Annede gebelikte GÜS** varlığı & 32 & 21.9 \\
\hline
\end{tabular}

**GÜS: Genitoüriner sistem enfeksiyonu

Bebekler RDS gelişip gelişmemiş olmasına göre 2 gruba ayrılıp risk faktörleri açısından karşılaştırıldığında gebelik haftasının ve doğum ağırlığının azlığı, 1. ve 5. dakika Apgar skorunun düşüklügü ve annede gebelikte hipertansiyon varlığının riski arttırdığı, gebelikte anneye steroit uygulanmış olmasının ise riski azalttığı görüldü. RDS ile bu risk faktörleri arasındaki ilişki Tablo 4'de verilmiştir.

Vakaların \%50,7'sinde $(\mathrm{n}=74)$ yenidoğan sarılığı görüldü. Yenidoğan sarılığıile ilgili olabilecek risk faktörleri değerlendirildiğinde; prematürelik derecesi, doğum ağırlığı ve 1. dakika Apgar skoru azaldıkça sarılık riskinin istatistiki olarak arttığı, Rh uygunsuzluğu varlığı ve anneye gebelikte steroit uygulaması varlığının da riski arttıran faktörler olduğu görüldü. YD sarıllı̆ı ve bu risk faktörleri arasındaki ilişki Tablo 5'de verilmiştir.

Çalışmamızda exitus, vakaların \%4,1'inde $(n=6)$ görülmüş olup; anlamlı risk faktörleri olarak; ikiz eşi olmak, hastaneye dış merkezden nakil yoluyla gelmiş olmak, doğum şeklinin normal vajinal yolla doğum olması, ayrıca prematürelik derecesinin, doğum ağırlığının, 1.

\begin{tabular}{|l|c|c|}
\hline \multicolumn{3}{|c|}{ Tablo 3: Vakalarda doğum sonrası tespit edilen patolojiler } \\
\hline & Sayı & Yüzde (\%) \\
\hline Yenidoğan Sarılı̆ı & 74 & 50.7 \\
\hline Respiratuar Distres Sendromu & 42 & 28.8 \\
\hline Patent Duktus Arteriosus & 18 & 12.3 \\
\hline Apne & 12 & 8.2 \\
\hline Pnömoni & 11 & 7.5 \\
\hline Bronkopulmoner Displazi & 10 & 6.8 \\
\hline Ventriküler Septal Defekt & 9 & 6.2 \\
\hline İntrakranial Kanama & 9 & 6.2 \\
\hline Rh uygunsuzluğu & 8 & 5.5 \\
\hline Atrial Septal Defekt & 8 & 5.5 \\
\hline Yenidoğan Konvulsiyonu & 7 & 4.8 \\
\hline Nekrotizan Enterokolit & 6 & 4.1 \\
\hline Mekonyum Aspirasyon Send. & 5 & 3.4 \\
\hline Prematür Retinopatisi & 2 & 1.4 \\
\hline Down Sendromu & 2 & 1.4 \\
\hline Trakeoözefageal Fistül & 2 & 1.4 \\
\hline Hipoksik İskemik Ensefalopati & 0 & 0.0 \\
\hline
\end{tabular}

dakika ve 5. dakika Apgar skorlarının düşüklüğü olarak tespit edilmiştir. Mortalite ve bunu etkileyen risk faktörleri Tablo 6'da verilmiştir.

\section{TARTIŞMA}

2012 yılında DSÖ tarafindan yayınlanan 184 ülkenin yer aldığı "Erken Doğum Hakkında Küresel Eylem Raporu”nda Dünya'da prematüre doğum oranlarının \%5-18 arasında değiştiği belirtilmiştir. Aynı raporda Türkiye için 2010 yılında prematüre doğum oranının \%11.9 olduğu belirtilmiştir (7).Yenidoğan mortalitesinin \%70'i, morbiditesinin ise $\% 75$ 'i prematür doğumlar nedeniyle olmaktadır (8). Bu nedenle prematüre doğumlar yüksek riskli yenidoğan grubunun en önemli kısmını oluşturmaktadır. Sahip oldukları farklı biyolojik yapı ve fizyolojik özelliklerin yanı sira, prematüre bebeklerin, respiratuvar distres sendromu, nekrotizan enterokolit, prematüre retinopatisi, intraventriküler kanama, bronkopulmoner displazi gibi ciddi morbidite risklerine sahip olması prognozu önemli ölçüde etkilemektedir (9). 


\begin{tabular}{|c|c|c|c|c|c|c|}
\hline & \multicolumn{2}{|c|}{ RDS yok } & \multicolumn{2}{|c|}{ RDS var } & \multicolumn{2}{|c|}{$P$ değeri } \\
\hline & Sayı & $\%$ & Sayı & $\%$ & & \\
\hline \multicolumn{7}{|l|}{ Gebelik yaşı } \\
\hline İmmatür & 1 & 16.7 & 5 & 83.3 & & \\
\hline İleri derecede prematüre & 7 & 31.8 & 15 & 68.2 & $\chi^{2}=36,2$ & $\mathrm{p}<0.0001$ \\
\hline - $\quad$ Orta derecede prematüre & 25 & 67.6 & 12 & 32.4 & & \\
\hline Sınırda prematüre & 71 & 87.7 & 10 & 12.3 & & \\
\hline \multicolumn{7}{|l|}{ Doğum Ağırlığı } \\
\hline ÇÇDDA & 2 & 33.3 & 4 & 66.7 & & \\
\hline ÇDDA & 14 & 46.7 & 16 & 53.3 & $\chi^{2}=17,8$ & $\mathrm{p}=0,0005$ \\
\hline DDA & 59 & 77.6 & 17 & 22.4 & & \\
\hline - $\quad$ NDA & 29 & 85.3 & 5 & 14.7 & & \\
\hline \multicolumn{7}{|l|}{ 1. dakika APGAR } \\
\hline - $\quad$ APGAR $0-4$ & 15 & 50.0 & 15 & 50.0 & & \\
\hline - $\quad$ APGAR 5-7 & 29 & 72.5 & 11 & 27.5 & $\chi^{2}=14,9$ & $\mathrm{p}=0.002$ \\
\hline - $\quad$ APGAR 8-10 & 38 & 90.5 & 4 & 9.5 & & \\
\hline - $\quad$ Bilinmiyor & 22 & 64.7 & 12 & 35.3 & & \\
\hline \multicolumn{7}{|l|}{ 5. dakika APGAR } \\
\hline - $\quad$ APGAR 0-4 & 0 & 0.0 & 5 & 100.0 & & \\
\hline - $\quad$ APGAR 5-7 & 14 & 51.9 & 13 & 48.1 & $\chi^{2}=25,4$ & $\mathrm{p}<0.0001$ \\
\hline - $\quad$ APGAR 8-10 & 68 & 85.0 & 12 & 15.0 & & \\
\hline - $\quad$ Bilinmiyor & 22 & 64.7 & 12 & 35.3 & & \\
\hline \multicolumn{7}{|l|}{ Antenatal HT } \\
\hline - $\quad$ HT yok & 61 & 64.9 & 33 & 35.1 & & \\
\hline - $\quad$ HT var & 43 & 84.3 & 8 & 15.7 & $\chi^{2}=8,6$ & $\mathrm{p}=0.014$ \\
\hline - $\quad$ Bilinmiyor & 0 & 0.0 & 1 & 100.0 & & \\
\hline \multicolumn{7}{|l|}{ Gebelikte Steroid Uygulaması } \\
\hline - $\quad$ Steroid Yapilmadi $\left(\chi^{2}=1,0\right)$ & 55 & 66.3 & 28 & 33.7 & & \\
\hline - 1 Doz Steroid $\left(\chi^{2}=2,8\right)$ & 9 & 52.9 & 8 & 47.1 & $\chi^{2}=9,3$ & $\mathrm{p}=0.009$ \\
\hline - 2 Doz Steroid $\left(\chi^{2}=5,6\right)$ & 40 & 87.0 & 6 & 13.0 & & \\
\hline
\end{tabular}

\begin{tabular}{|c|c|c|c|c|c|c|}
\hline & \multicolumn{2}{|c|}{ Sarılık yok } & \multicolumn{2}{|c|}{ Sarılık var } & \multicolumn{2}{|c|}{$P$ değeri } \\
\hline & Sayı & $\%$ & Sayı & $\%$ & & \\
\hline \multicolumn{7}{|l|}{ Prematürelik } \\
\hline - İmmatür & 4 & 66.7 & 2 & 33.3 & & \\
\hline İleri derecede prematüre & 5 & 22.7 & 17 & 77.3 & $\chi^{2}=8,2$ & $\mathrm{p}=0.042$ \\
\hline - $\quad$ Orta derecede prematüre & 18 & 48.6 & 19 & 51.4 & & \\
\hline - $\quad$ Sinırda prematüre & 45 & 55.6 & 36 & 44.4 & & \\
\hline \multicolumn{7}{|l|}{ Doğum Ağırlığı } \\
\hline - ÇÇDDA & 3 & 50.0 & 3 & 50.0 & & \\
\hline - $\quad$ ÇDDA & 9 & 30.0 & 21 & 70.0 & $\chi^{2}=10,8$ & $\mathrm{p}=0.013$ \\
\hline - $\quad$ DDA & 36 & 47.4 & 40 & 52.6 & & \\
\hline - $\quad$ NDA & 24 & 70.6 & 10 & 29.4 & & \\
\hline \multicolumn{7}{|l|}{ 1. dakika APGAR } \\
\hline - $\quad$ APGAR 0-4 & 7 & 23.3 & 23 & 76.7 & & \\
\hline - $\quad$ APGAR 5-7 & 19 & 47.5 & 21 & 52.5 & $\chi^{2}=13,4$ & $\mathrm{p}=0.004$ \\
\hline - $\quad$ APGAR 8-10 & 28 & 66.7 & 14 & 33.3 & & \\
\hline - $\quad$ Bilinmiyor & 18 & 52.9 & 16 & 47.1 & & \\
\hline \multicolumn{7}{|l|}{ Rh uygunsuzluğu } \\
\hline Yok & 70 & 50.7 & 68 & 49.3 & & \\
\hline - Var & 2 & 25.0 & 6 & 75.0 & $\chi^{2}=2,0$ & $\mathrm{p}=0.157$ \\
\hline \multicolumn{7}{|c|}{ Gebelikte Steroid Uygulaması } \\
\hline - $\quad$ Steroid Yapılmadı $\left(\chi^{2}=3,9\right)$ & 50 & 60.2 & 33 & 39.8 & & \\
\hline - 1 Doz Steroid $\left(\chi^{2}=4,5\right)$ & 4 & 23.5 & 13 & 76.5 & $\chi^{2}=10,4$ & $\mathrm{p}=0.006$ \\
\hline - 2 Doz Steroid $\left(\chi^{2}=1,9\right)$ & 18 & 39.1 & 28 & 60.9 & & \\
\hline
\end{tabular}




\begin{tabular}{|c|c|c|c|c|c|c|}
\hline & \multicolumn{2}{|c|}{ Exitus } & \multicolumn{2}{|c|}{ Şifayla Taburcu } & \multicolumn{2}{|c|}{$P$ değeri } \\
\hline & Sayı & $\%$ & Sayı & $\%$ & & \\
\hline \multicolumn{7}{|l|}{ Prematürelik } \\
\hline - $\quad$ İmmatür & 3 & 50.0 & 3 & 50.0 & & \\
\hline - $\quad$ İleri derecede prematüre & 1 & 4.5 & 21 & 95.5 & $\chi^{2}=35,7$ & $\mathrm{P}<0.0001$ \\
\hline - $\quad$ Orta derecede prematüre & 2 & 5.4 & 35 & 94.6 & & \\
\hline - $\quad$ Sinırda prematüre & 0 & 0.0 & 81 & 100.0 & & \\
\hline \multicolumn{7}{|l|}{ Doğum Ağırlığı } \\
\hline - $\quad$ ÇÇDDA & 2 & 33.3 & 4 & 66.7 & & \\
\hline - $\quad$ ÇDDA & 3 & 10.0 & 27 & 90.0 & $\chi^{2}=18,6$ & $\mathrm{p}=0.0003$ \\
\hline - $\quad$ DDA & 1 & 1.3 & 75 & 98.7 & & \\
\hline - $\quad$ NDA & 0 & 0.0 & 34 & 100.0 & & \\
\hline \multicolumn{7}{|l|}{ 1. dakika APGAR } \\
\hline - $\quad$ APGAR 0-4 & 1 & 3.3 & 29 & 96.7 & & \\
\hline - $\quad$ APGAR 5-7 & 0 & 0.0 & 40 & 100.0 & $\chi^{2}=13,2$ & $\mathrm{p}=0.001$ \\
\hline - $\quad$ APGAR 8-10 & 0 & 0.0 & 42 & 100.0 & & \\
\hline - $\quad$ Bilinmiyor & 5 & 14.7 & 29 & 85.3 & & \\
\hline \multicolumn{7}{|l|}{ 5. dakika APGAR } \\
\hline - $\quad$ APGAR 0-4 & 1 & 20.0 & 4 & 80.0 & & \\
\hline - $\quad$ APGAR 5-7 & 0 & 0.0 & 27 & 100.0 & $\chi^{2}=17,5$ & $\mathrm{p}=0.001$ \\
\hline - $\quad$ APGAR 8-10 & 0 & 0.0 & 80 & 100.0 & & \\
\hline - $\quad$ Bilinmiyor & 5 & 24.7 & 29 & 85.3 & & \\
\hline \multicolumn{7}{|l|}{ İkiz eşi olma } \\
\hline - $\quad$ İkiz eşi & 3 & 14.3 & 18 & 85.7 & & \\
\hline - $\quad$ İkiz eşi değil & 3 & 2.4 & 122 & 96.8 & $\chi^{2}=6,4$ & $\mathrm{p}=0.01$ \\
\hline \multicolumn{7}{|l|}{ Nakil durumu } \\
\hline - $\quad$ Hastanemizde doğum & 1 & 0.9 & 105 & 99.1 & & \\
\hline - $\quad$ Diş merkezden nakil & 5 & 12.5 & 35 & 87.5 & $\chi^{2}=10,2$ & $\mathrm{p}=0.006$ \\
\hline \multicolumn{7}{|l|}{ Doğum Şekli } \\
\hline - $\quad$ Normal doğum & 4 & 14.3 & 24 & 85.7 & & \\
\hline - $\quad$ Sezeryan & 2 & 1.7 & 116 & 98.3 & $\chi^{2}=9,1$ & $\mathrm{p}=0.003$ \\
\hline
\end{tabular}

Vakalarımızın doğum ağırlığına ve gebelik haftasına göre sinıflandırılmasında çoğu sınırda prematüre ve düşük doğum ağırlığı grubunda yer ald1, bu daha önce bildirilen literatürler ile uyumluydu $(6,10,11)$.

Çalışmamızda yer alan vakaların dörtte birinden fazlası (\%27.4) hastanemiz dışında doğup nakil yoluyla ünitemize gelmiştir. $\mathrm{Bu}$ durum, hastanemizde doğup ünitemize yatırılan prematürelerle nakil öyküsü olan prematürelerin karşılaştırılmasına olanak sağlamıştır. Ancak, nakil öyküsü olan prematürelerin nakil öncesi klinik durumları ve nakil şartları ile ilgili elimizde veri bulunmadığ 1 için; bu karşılaştırmanın, prematürelerin nakil öyküsünün etkilerini ortaya koymakta yeterli olmadığı düşünülmektedir.
Çalışmamızda yer alan vakaların büyük çoğunluğu $(\% 79,5)$ sezeryan doğumla dünyaya gelmişti. Bu durum çalışmanın yapıldığı kurumun 3. basamak bir sağlık kuruluşu olması ve çoğunlukla çevre merkezlerden yönlendirilmiş riskli gebeliklerin fazla oranda bulunmasina bağlanmıştır. Vakaların \%14.4'ü ikiz eşiydi. İkiz bebek oranının normal topluma göre fazla olması; çoğul gebeliğin, prematürite ve immatürite ile doğrudan ilişkili olmasıyla açıklanabilir.

Annelere ait faktörlerden sigara kullanımı, erken membran rüptürü, hipertansiyon, gestasyonel diabet, genitoüriner sistem enfeksiyonu varlığ1 sorgulanmış olup premature doğumlar için risk faktörleri arasında olan bu 
durumlar literatürle uyumlu şekilde yüksek bulunmuştur $(2,6,10)$.

RDS prematürelerin mortalite ve morbiditesini belirleyen önemli klinik tablolardan biri olup çalışmamızda gebelik haftasının ve doğum ağırlığının azlığı, 1. ve 5. dakika Apgar skorunun düşüklüğü ve annede gebelikte hipertansiyon varlığının riski arttırdığı, gebelikte anneye steroit uygulanmış olmasının ise riski azalttığ1 görülmüştür $(12,13)$. Literatürde maternal hipertansiyonun, fetal akciğer maturasyonunu hızlandırdığını ve bu yolla RDS açısından koruyuculuk sağladığını öne süren çalışmalar olduğu gibi aksini iddia eden çalışmalar da mevcuttur (14-16). Prenatal steroid tedavisinin fetal akciğer maturasyonunu arttırdığı bugüne kadar yapılan birçok çalışma ile ortaya konmuştur (17-19). Crowley ve arkadaşlarının metaanalizinde antenatal steroid tedavisinin RDS'yi \%50 oranında azalttığı bildirilmiştir (20). Bizim çalışmamızda da gebelikte steroid uygulanmasının RDS sıklığını azalttı̆̆1 saptanmıştır. Gebelikte steroid tedavisi uygulanmayan annelerin bebeklerinde RDS \%33,7 oranında görülürken, 1 doz steroid uygulananlarda $\% 47,1,2$ doz steroid uygulananlarda ise \%13.0 oranında görüldüğü saptandı. $1 \mathrm{doz}$ steroid uygulanmasının RDS sıklığında anlamlı değişiklik yapmadığı, ancak 1 doz ve 2 doz steroid uygulaması arasında anlamlı fark bulunmuştur. $\mathrm{Bu}$ durum 2 doz steroid uygulanmasinın RDS sıklığında anlamlı değişiklik oluşturabileceğini ve steroid kullanımıyla ilgili hasta yakınlarından aldığımız bilgilerin yetersiz olduğunu düşündürmektedir.

Bronko pulmoner displazi sıklığı Türkiye'deki merkezlerde \%2,3-10,5 arasında bildirilmiştir (21). Bizim çalışmamızda da BPD sıklığı bu aralığa uygundur ve $\% 6,8$ oranındadır. Prematürite ve düşük doğum ağırlığı, bronkopulmoner displazinin gelişiminde önemli bir risk faktörüdür (22). Wolfgang ve arkadaşlarının çalışmasında; 26 gebelik haftasından küçük olan prematürelerde BPD oranını \%40.4, 26-27 gebelik haftasında olanlarda \%51, 28-31 gebelik haftasında olanlarda \%19.3 olarak bildirilmiştir(23). Aldemir ve ark. çalışmasında BPD sıklığ1; 28 gebelik haftası altında olan prematürelerde \%37, 28-31 hafta olanlarda $\% 50,32$ haftadan büyük olanlarda ise $\% 11$ olarak rapor edilmiştir(24). Zonguldak ilinde yapılmış bir çalışmada; gebelik yaşı 23-25 hafta olan bebeklerde BPD sıklığı \%28,1, 26-29 hafta olan bebeklerde \%22,5, 30-33 hafta olan bebeklerde \%2,9, 34-36 hafta olan bebeklerde ise $\% 0,9$ bulunmuştur (25). Bizim çalışmamızda ise BPD sıklığı gebelik yaş1 28 haftadan küçüklerde $\% 33,3,28-32$ hafta olanlarda \%22,7, 32-34 hafta olanlarda $\% 8,1,34$ haftadan büyük prematürelerde ise \%0,0'dır. Gebelik haftası gruplandırmalarının farklılığından kaynaklanan uyumsuzluklar olmakla birlikte çalışmamızda olduğu gibi diğer çalışmalarda da BPD sıklığının gebelik yaşı küçüldükçe arttı̆̆ı görülmüştür.

Çalışmamızda, pnömoni için risk faktörü olarak bilinen prematürelik derecesi, düşük doğum ağırlığı ve mekanik ventilasyon uygulamasının pnömoni ile anlamlı ilişkisi tespit edilememiş, dış merkezden nakil olmanın ise pnömoni sıklığını arttırdığı gözlenmiştir. Nakille gelen vakaların \%20'sinde pnömoni görülürken, doğumu hastanemizde prematürelerin \%2,8'indepnömoni görülmüştür.

Çalışmamıza dâhil edilen vakaların yarısından fazlasında yenidoğan sarılığı görülmüştür. Hastaların değerlendirilmesi sonucu immatür olanlar ve çok çok düşük doğum ağırlıklı olanlar hariç tutulursa; gebelik haftası ve doğum ağırlığ1 azaldıkça yenidoğan sarılığ 1 riskinin arttığ1 görülmüştür. $\mathrm{Bu}$ durum gebelik haftasına göre immatür olanların ve çok çok düşük doğum ağırlıklı olanların daha az sayıda olmalarıyla açıklanabilir. Çalışmamızda, yenidoğan sarılığı ile $\mathrm{Rh}$ uygunsuzluğu arasında anlamlı ilişki saptanmamıştır. Antenatal steroid uygulamasının yenidoğan sarılığını arttırdığı gözlenmiştir. Önceki çalışmalarda; yenidoğan sarılığ1 için hastaneden erken taburculuk, ailenin ilk çocuğu olma, erkek 
cinsiyet, annesütü ile beslenme, \% 10'u geçen kilo kaybı ve önceki kardeşte fototerapi alma hikâyesi olması risk faktörleri olarak tespit edilmiştir. $(26,27)$. BülBül ve ark. çalışmasında ise farklı olarak annesütü harici beslenme, normal vajinal yolla doğum ve çocuğun ailenin 2 . veya daha sonraki çocuklarından birisi olması risk faktörü olarak tespit edilmiştir (28).

Düşük doğum ağırlığ1 ve prematurite infant mortalitesinin en önemli risk faktörleridir (29). Canlı doğumların ölümle sonuçlanma oranı normal doğum ağırlıklı bebeklerde \%0,22 iken, çok düşük doğum ağırlıklı bebeklerde \% 23' lere çıkmaktadır (30). Aynı şekilde gebelik haftası 37 38 hafta arası olanlarda mortalite görülme sıklığ $\% 0,3$ olup, gebelik haftas $1<32$ hafta olanlarda bu oran $\% \quad 17$ leri bulmaktadır (30). Prematürelerdeki mortaliteyi arttıran diğer risk faktörleri arasında; az gelişmiş ülkelerdeki doğumlar, intra uterin gelişme geriliği, BPD, hipoksik beyin hasarı, prematüre retinopatisi, infeksiyonlar ve kardiopulmoner resusitasyon uygulanmış olması yer almaktadır (31-34). Bizim çalışmamamızda da gebelik haftasının ve doğum ağırlığının düşüklüğü belirgin bir risk faktörü olarak saptanmış, ayrıca 1. ve 5. dakika Apgar skorlarının düşüklüğü, ikiz eşi olma, dış merkezden nakil yoluyla gelme ve normal vajinal yolla doğum diğer risk faktörleri olarak belirlenmişlerdir.

Sonuç olarak;

Prematüre doğum, yenidoğan mortalite ve morbiditesinin en önemli nedenidir. $\mathrm{Bu}$ nedenle gebelikte hipertansiyon, diyabet, erken membran rüptürü, genitoüriner sistem enfeksiyonu gibi durumların prematürite için risk faktörü olduğu bilinmeli ve antenatal takiplerin daha düzenli yapılması sağlanmalıdır.

Prematür bebeklerin uygun personel ve teknik ekipmanın bulunduğu yenidoğan yoğun bakım ünitesinde takibiyle olası RDS, Bronkopulmoner displazi, NEK, İKK, HİE, ROP gibi mortalite ve morbidite nedenleri azaltılabilir. $\mathrm{Bu}$ durumda riskli gebeliklerin intrauterin transportu dolayısıyla prematüre bebeğin yenidoğan yoğun bakım ünitesi bulunan bir merkezde doğması klinik problemlerin sayısını ve şiddetini azaltacaktır.

\section{KAYNAKLAR}

1. Blencowe H, Cousens S, Oestergaard MZ, Chou D, Moller AB, Narwal R, Adler A, Vera Garcia C, Rohde S, Say L, Lawn JE. National, regional, and worldwide estimates of preterm birth rates in the year 2010 with time trends since 1990 for selected countries: a systematic analysis and implications. Lancet. 2012;379(9832):2162.

2. Buyru F. Anne Hastalıklarının Fetüs ve Yenidoğana Etkileri. In: Dağoğlu T, Ovalı F, (ed). Neonatoloji. İkinci baskı. İstanbul: Nobel Tip Kitabevi, 2007:99,100.

3. Ward RM, Beachy JC. Neonatal complications following preterm birth. Br J Obstet Gynaecol, 2003;110 (20): 8-16.

4. March of Dimes White Paper on Preterm Birth The Global and Regional Toll March of Dimes Foundation White Plains, New York. Accessed on November 2, 2009.

5. Türk Neonatoloji Derneği Çok Merkezli Çalışma Grubu. Türkiye'de perinatal mortalite-1999. Türk Neonatoloji Derneği Bülteni, 3: 8-12, 2001.

6. Dağoğlu T. Yurdakök M, Erdem G (Editörler). Neonatoloji'de Prematürite, s.123- 9, Güneş Tip Kitapevi, Ankara, 2004.

7. Okumuş N. Prematüre ve Sorunlarına Genel Bakış. In: Numan O. (Ed.). Hayata Prematüre Başlayanlar, Aysun Yayıncilık, Ankara, 2012, s:13,14.

8. Tezcan S. Türkiye'de bebek ve çocuk ölümleri. Üçdilek Matbaası, Ankara, 1985; 41-2.

9. Carlo WA. The high-risk infant. In: Behrman RE, Kliegman RM et al. (editors). Nelson Textbook of Pediatrics. 19th edition, Elseiver Saunders Company; 2011: s.552-64.

10. Can G, İnce Z. Preterm doğanlar, intrauterin büyüme geriliği, makrozomi, çoğul gebelik. In: Neyzi O, Ertuğrul T, (ed). Pediatri cilt I, İstanbul: Nobel Tip Kitabevi, 2010: s.367-9.

11. Engle WA. A recommendation for the definition of "Late preterm" (near- term) and the birth weight-gestational age classification system. Semin Perinatol 2006;30:2-7.

12. İnce $Z$, Çoban A. Yenidoğanda solunum sorunları. In: Ertuğrul T, Neyzi O, editörler. Pediyatri. Dördüncü baskı. İstanbul: Nobel Tip Kitabevleri, 2010: 423-43.

13. Ovalı F. Solunum sıkıntısı ve respiratuar distres sendromu. In: Dağoğlu T, Ovalı F, editörler. Neonatoloji. İkinci baskı. İstanbul: Nobel Tıp Kitabevi, 2007:331-346.

14. Chiswick ML. Prolonged rupture of membranes,preeclamptic toxemia and respiratory distress syndrome. Arch Dis Child, 1976; 51: 674-679.

15. Yoon JJ, Kohl S, Harper RG. The relationship between maternal hypertensive disease of pregnancy and the 
incidence of idiopathic respiratory distress syndrome. Pediatrics, 1980; 65: 735-739.

16. Schiff E, Friedman SA, Mercer BM, Sibai BM. Fetal lung maturity is not accelerated in preeclamptic pregnancies. Am J Obstet Gynecol, 1993; 169: 1096-1101.

17. Ward RM. Pharmacologic enhancement of fetal lung maturation. Clin Perinatol 1994; 21: 523-542.

18. Kari MA, Hallman M, Eronen M, et al. Prenatal dexamethasone treatment in conjunction with rescue therapy of human surfactant: a randomized placebo-controlled multicenter study. Pediatrics 1994;93: 730-736.

19. Brazilian Neonatal Research Network. Antenatal corticosteroid use and clinical evolution of preterm newborn infants. J Pediatr (Rio J) 2004; 80: 277-284.

20. Crowley P, Chalmers I, Keirse MJ. The effects of corticosteroid administration before preterm delivery: an overview of the evidence from controlled trials. Br J Obstet Gynaecol 1990; 97: 11-25.

21. Duman N, Kumral A, Gulcan H, Ozkan H. Outcome of very low birth weight infants in a developing country: a prospective study from the western region of turkey. J Matern Fetal Neonatal Med. 2003; 13:54-58.

22. Jobe AH, Bancalari E. Bronkopulmonary dysplasia. Am J Respir Crit Care Med. 163: 1723-1729, 2001.

23. Thomas W, Speer CP. Manegement of infants with bronchopulmonary dysplasia in Germany. Early Human Development. 81;155-163, 2005.

24. Aldemir EY, Kavuncuoğlu S, Kayrak EA et al. Yaşatılan riskli pretermlerde önemli bir sorun bronkopulmoner displazi ve iki yıllık sonuçlarımız. 13. Ulusal Neonatoloji Kongresi (UNEKO-13) Nisan 2005;PY: 140, 2005.

25. Çil MA. Yenidoğan Ünitesinde Prematürite Tanısı ile Yatan Bebeklerin Retrospektif Değerlendirilmesi, Tıpta Uzmanlık
Tezi, ZKE Üniversitesi, Tıp Fakültesi, Çocuk Sağlığı ve Hastalıkları, Zonguldak, 2010.

26. Gartner LM. Neonatal jaundice. Pediatr Rev. 1994;15(11):422-432. doi: 10.1542/pir.15-11-422.

27. Hansen TW. Guidelines for treatment of neonatal jaundice. Is there a place for evidence-based medicine? Acta Paediatr. 2001;90(3):239- 241. doi: $10.1111 /$ j.16512227.2001.tb00297.

28. Bulbul A, Cayonu N, Sanli ME, Uslu S. Evaluation of risk factors for development of severe hyperbilirubinemia in term and near term infants. Pak J Med Sci 2014;30(5):1113-1118.

29. Mathews TJ, MacDorman MF. Infant mortality statistics from the 2005 period linked birth/infant death data set. Natl Vital Stat Rep. 2008;57(2):1.

30. Mathews TJ, MacDorman MF. Infant mortality statistics from the 2005 period linked birth/infant death data set. Natl Vital Stat Rep. 2008;57(2):1.

31. Katz J, Lee AC, Kozuki N, et al. Mortality risk in preterm and small-for-gestational-age infants in low-income and middle-income countries: a pooled country analysis. Lancet $2013 ; 382: 417$

32. Zeitlin J, El Ayoubi M, Jarreau PH, et al. Impact of fetal growth restriction on mortality and morbidity in a very preterm birth cohort. J Pediatr 2010; 157:733.

33. Bassler D, Stoll BJ, Schmidt B, et al. Using a count of neonatal morbidities to predict poor outcome in extremely low birth weight infants: added role of neonatal infection. Pediatrics 2009; 123:313.

34. Wyckoff MH, Salhab WA, Heyne RJ, et al. Outcome of extremely low birth weight infants who received delivery room cardiopulmonary resuscitation. J Pediatr 2012; 160:239. 